\title{
Long-term effect of eco-driving education on fuel consumption using an on-board logging device
}

\author{
B. Beusen \& T. Denys \\ Department of Energy Technology, VITO, Belgium
}

\begin{abstract}
This paper describes the measured long-term effects on fuel consumption of ecodriving education. The results are part of the long-term survey within the Flemish research program "An activity-based approach for surveying and modelling travel behaviour". During several months, the travel and driving behaviour of 28 respondents was monitored. The methodology consists of using an on-board vehicle device and a web-application. The on-board device is equipped with a GPRS-modem, a WiFi connection, a GPS system and a CANinterface. The GPS system allows the monitoring of travel behaviour. Driving behaviour is studied by logging various CAN-parameters (e.g. revs per minute, chosen gear etc). Data is transmitted to a central server through the GPRSnetwork. Alternatively, data can be transmitted using a WiFi connection when present. Respondents can access the data on a web-application and provide additional information. The gathered information is used on the one hand to develop a regional activity-based travel model (not discussed in this paper). On the other hand, the data is used to assess the long-term effect of an eco-driving course by analyzing the change in driving behaviour and monitoring fuel consumption, and using these inputs to simulate the emissions before and after such training. The data might also be used as feedback to the driver, to visualize his driving behaviour, and to help him understand what he can do to further improve his driving style. This paper discusses the long-term effect of an ecodriving course on fuel economy and driving style for eight participants.
\end{abstract}

Keywords: on-board logging device, eco-driving, fuel consumption, driving behaviour, driving style, CAN. 


\section{Introduction}

Recently policy makers are developing an increased interest in fuel-efficient driving behaviour, commonly known in Europe as 'eco-driving'. The focus here lies on reducing greenhouse gas emissions from vehicles, and at the same time benefiting from the positive effect a more steady driving style has on road safety [1]. Several countries in Europe are incorporating the promotion of fuel efficient driving behaviour in their policies, claiming that fuel savings can mount up to $10 \%$ or more $[1,2]$. Furthermore, driving style differences have been shown to have significant impacts on emissions [3] and are thus of importance to policies that try to reduce emissions $[4,5]$. Also environmental groups are disseminating information on fuel efficient driving, as well as insurance institutions [6, 7].

Several studies have indeed proven the short-term effect of fuel efficient driving [8-13], but only a few have studied the effect on the longer term. Where short-term studies indicate fuel saving potentials of $10 \%$ or even more, the few studies covering a longer period conclude that fuel consumption decreases only by $2 \%[14,15]$.

This paper describes the preliminary results of an ongoing survey with a duration of one year, using an on-board vehicle device for the collection of data regarding driving behaviour. The survey's results on driving behaviour will provide insight into the long-term effects of training on fuel efficient driving and will eventually contribute to better methods for emission estimation [16].

\section{Previous studies using in-vehicle data recorders}

In-vehicle data recorders (IVDR) are on-board devices that record information about the movement, control and performance of the vehicle [17]. The first application of onboard data loggers, commonly known as in-vehicle data recorders (IVDR), was the 'Event Data Recorder' (EDR) which collects technical and driverrelated data in the seconds just before, during and immediately after a crash. In the last couple of years, EDR technology is becoming standard equipment in cars, and is mostly implemented as an extra functionality in the airbag control system.

Lately, the functionality of in-vehicle data recorders has been extended to also record non-crash related information. A number of IVDR systems have been developed in recent years. While their details and capabilities vary, the information they commonly collect may be classified in several categories [18]:

1. Vehicle movement, which includes the longitudinal and lateral accelerations and the speed of the vehicle.

2. Driver control, which includes variables such as the engine throttle and brake application and wheel-angle.

3. Engine parameters, such as RPM.

4. State of the vehicle safety systems, such as air bags, seat belts, ABS and traction control.

5. Vehicle location, using GPS systems.

6. Time.

7. Visual documentation both inside and outside the vehicle. 
Several studies that investigated the effects of feedback to the driver on their driving behaviour through the use of IVDR technology, suggested that this feedback leads to increased traffic safety [19, 20]. Although these studies showed the positive effect of IVDR technology on traffic safety, there's only limited knowledge on what data should be collected, and how the data should be interpreted and analyzed. For example, it's not yet clear how second-by-second acceleration profiles might translate into crash risk numbers [18].

Most studies using IVDR-technology focused primarily on driving behaviour in the context of traffic-safety. To our knowledge, IVDR-technology has not yet been used in many studies linking fuel economy to driving behaviour in a largescale long-term survey.

\section{Methodology for this experiment}

To perform data collection in this long-term driving monitoring experiment, VITO uses an on-board device to monitor and $\log$ the necessary parameters. The onboard device is equipped with a memory card, a GPRS-modem, a WiFi connection, a GPS tracking system and is connected in parallel with the Controller Area Network (CAN) of the vehicle. This configuration allows monitoring and logging 2 types of data: the position and speed of the vehicle by means of the GPS tracking system as well as electronic engine data extracted from the CAN-bus, which includes data on mileage, number of revolutions per minute, engine temperature, position of the accelerator, gear selection, instantaneous fuel consumption and coolant temperature. For some cars, not all relevant CAN-data can be read. The logging device is small (approximately 10 by 10 by $3 \mathrm{~cm}$ ) and is installed out of sight of the driver. All data are stored on the internal memory card of the on-board logger and transmitted daily to a central server via the GPRSmodem. On the server, all data is entered into a database.

The data transmission can be performed on a real time basis or in batch, for example during the night when mobile communication activity and costs are low. Due to the long duration of the trial period in this project, data are only transmitted at night.

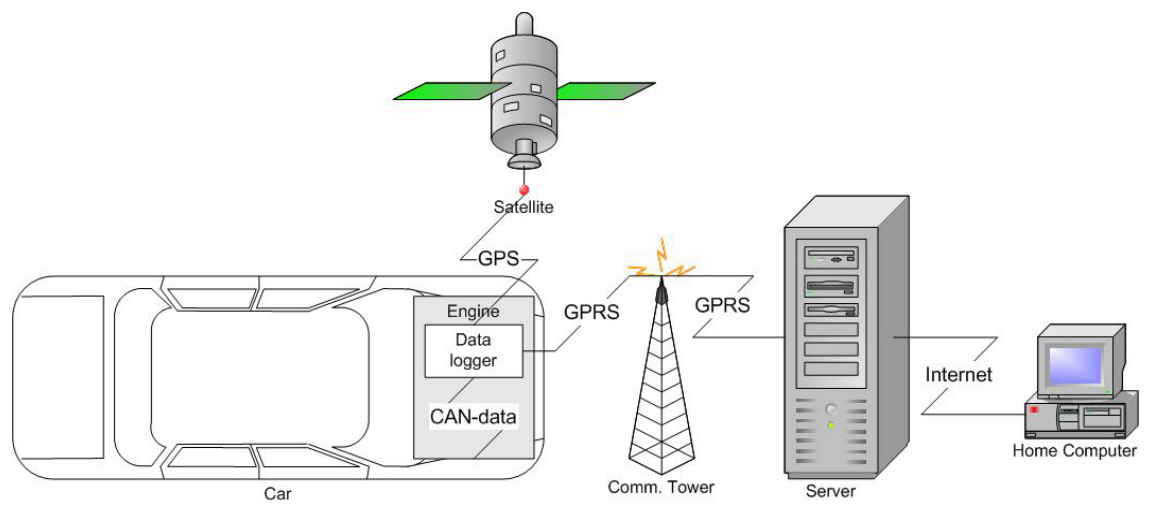

Figure 1: General set-up of long-term survey. 
The combination of GPS and CAN-data allows us to relate the measured speed, throttle position, fuel consumption, etc. to the road infrastructure. For example, the measured speed can be compared to the speed limit on that particular road segment, indicating whether or not the driver is speeding. Also the driving behaviour in the neighbourhood of speed control cameras can be investigated, to check to what amount drivers brake when passing a speed control camera. This kind of behaviour has an effect on traffic safety. These are just a few examples of the possibilities provided by the experimental set-up.

In this study, an analysis of the long-term effect of training on fuel efficient driving is foreseen. Halfway through the project, the participants are given a course of 4 hours on fuel efficient driving. At the moment of this writing, 12 participants have already taken the course, of which 8 drive a car that allows to monitor their fuel consumption, and who's car is not shared with other drivers. Another 16 participants will take the course within the weeks to come. Average fuel consumption is being monitored and analyzed before and after the course, allowing one to make a comparison before and after the training. The driver behaviour continues to be monitored for another 6 months after the training, so that the long-term effect can be assessed. In addition, parameters characterizing the driving behaviour are monitored as well. These include speed, revolutions per minute, gear selection, engine temperature and position of the accelerator.

The data concerning instantaneous fuel consumption and travel distance is used to calculate the effect the training on fuel efficient driving had on the average fuel consumption of the participants. Parameters like speed (and its derivatives acceleration and deceleration), number of revolutions, engine temperature, position of the accelerator and gear selection will allow a characterization of the participants' driving behaviour. In this way, the driving behaviour before and after the training can be compared. This allows one to assess the extent to which the training induced a behavioural change.

\section{Driving style characterization}

The data recording phase of the project is still ongoing. Nevertheless, 12 participants already have taken a course a fuel efficient driving, and for 8 of them a comparison can be made between the fuel consumption before and after they had taken the course. The 4-hour course included one test-drive per participant without any comment or information of the instructor. The test-drive was followed by a theoretical presentation of approximately one hour about the eco-driving principles. To conclude the course, a second test-drive for every participant was performed, this time with feedback from the instructor in the car.

The different eco-driving aspects, which can be used to characterize a person's driving style, are discussed below as these have a potential impact on fuel consumption. The data results are investigated to see if the fuel efficient driving course led to a change in driving behaviour for the participants and consequently to a change in fuel consumption. The aspects of a person's driving style that are looked at in this study, include the gear shifting behaviour, 
acceleration and deceleration profiles, relative positive acceleration, and the relative amount of letting the car roll in gear.

\subsection{Gear shifting behaviour}

On of the most important rules for fuel efficient driving is to shift up early when accelerating (between 2000 and $2500 \mathrm{rpm}$ ). Figure 2 shows the histogram of the engine revolutions per minute (rpm) at which one particular driver changed to a higher gear. Data is displayed for two sets of data: one of several weeks before, one of several weeks after the eco-driving course. The rpm data was classified in groups of $100 \mathrm{rpm}$. The $\mathrm{Y}$-axis represents the percentage of shifting points in this category compared to the total number of up-shifting actions.

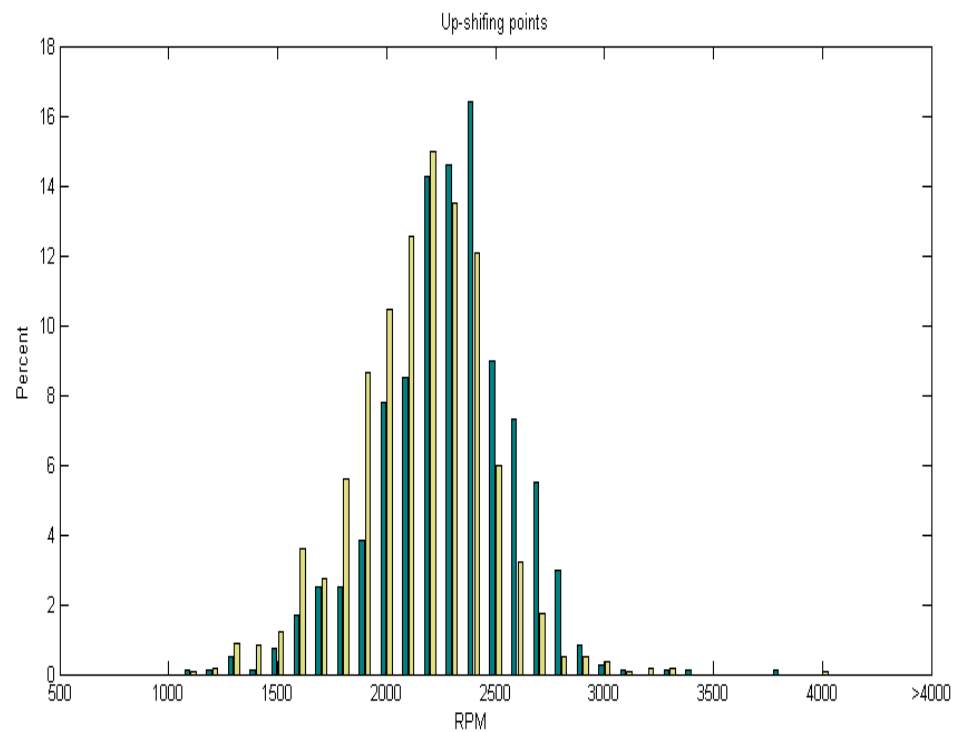

Figure 2: Histogram of shifting points (one gear up) before (dark grey) and after (light grey) an eco-driving course.

The mean rpm value of gear-changes to a higher gear is used as a possible factor influencing the measured fuel consumption when comparing data from 'before' and 'after' the eco-driving course for a particular diver.

\subsection{Acceleration-deceleration profile}

Eco-driving requires smooth acceleration and gradual braking or letting the car roll in gear. Faster accelerations lead to an increased fuel consumption. When approaching a cross-road or red traffic lights, maintaining a high speed in order to suddenly brake hard before coming to a complete stop, wastes fuel. 
Accelerations and deceleration of the vehicles in this experiment are calculated on a second-by-second base as a first derivative of the speed data. On the basis of a histogram of the acceleration data, it was decided to use the relative amount of acceleration actions greater than $2 \mathrm{~m} / \mathrm{s}^{2}$ as an indicator for an aggressive driving style.

Since sharper accelerations are possible at low speed and in low gears, high power demand at high speeds will not be visible using an acceleration threshold. Therefore, the relative positive acceleration (RPA) is also calculated. The RPA is calculated as 'speed $x$ acceleration' on a second-by-second basis. From the RPA histogram, it was concluded to use an RPA $=15 \mathrm{~m}^{2} / \mathrm{s}^{3}$ as a threshold for a 'large' RPA, indicating aggressive driving.

\subsection{Roll out in gear}

Fuel efficient driving asks for a smooth deceleration when approaching crossroads or traffic lights. With the foot off the accelerator pedal, and the car still in gear, fuel consumption in modern cars drops to zero. A slower approach to red traffic lights also leaves the driver with more time for the lights to turn green during his approach, possibly avoiding a complete stop.

The relative time a driver lets the car roll while still in gear, is used a possible factor influencing the measured fuel consumption when comparing data from before and after the eco-driving course.

\section{Fuel consumption results}

Fuel consumption raw data is measured on a second-by-second basis. From the raw data, an average fuel consumption is calculated for every week (total fuel consumption divided by the total distance). The time-interval of one week is chosen because most trips people make are the same week after week (e.g. home to work on Monday to Friday), while this time interval is small enough to allow for a time series comparison (evolution of fuel consumption week after week) during the several months of monitoring. An example of weekly averages for one particular driver is shown in figure 3 below (eco-driving course in week 11).

For 8 drivers, the weekly fuel consumption was measured over a period of several months (1 to 6 months) as a baseline for comparison. After these measurements, the drivers took a course on fuel efficient driving (eco-driving), after which the measuring of fuel consumption continued and is still ongoing at this moment.

The weekly fuel consumption averages were then compared before and after the drivers took the eco-driving course, to check whether a change in fuel consumption can be observed. Also weekly averages were calculated for the rpm at which drivers changed to higher gears, for the relative amount of fast accelerations, for large RPA values, and for the relative amount of time the driver lets the car roll in gear. It is expected that changes in these factors mentioned above, will lead to a change in fuel consumption. The results for one vehicle are shown as an example in table 1. 


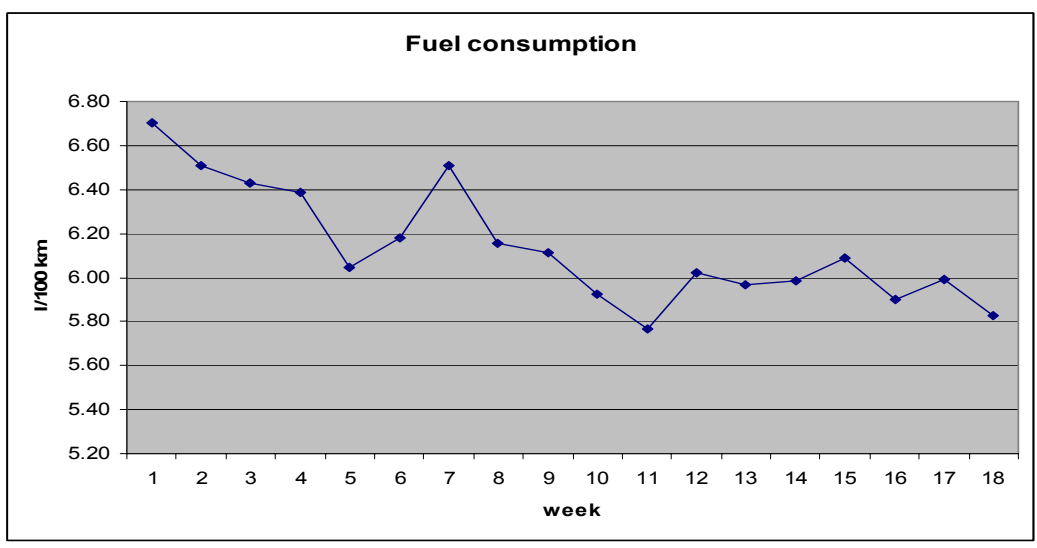

Figure 3: Weekly fuel consumption averages for one driver.

Table 1: Data for one vehicle, incorporating results on distance over which the measurement took place, time-frame (weeks) of measurement, the average gear-shifting point, percentage of distance rolling out in gear, percentage of fast accelerations and large RPA-values.

\begin{tabular}{rcccccccc}
\hline Vehicle & $\begin{array}{c}\mathbf{I} / \mathbf{1 0 0} \\
\mathbf{k m}\end{array}$ & distance & weeks & $\begin{array}{c}\text { gear- } \\
\text { shifts }\end{array}$ & roll-out & $\begin{array}{c}\text { fast } \\
\text { acc }\end{array}$ & RPA \\
1 & & & & 2316 & 6.1 & 0.11 & 2.58 \\
& pre & 8.22 & 6419 & 14 & 23.19 & \\
post & 7.62 & 2987 & 6 & 2193 & 7.23 & 0.1 & 1.87 \\
& diff & $-7.30 \%$ & & & -123 & $18.52 \%$ & $-9.09 \%$ & - \\
\hline
\end{tabular}

Table 2: Overview of long-term fuel savings achieved after an eco-driving course.

\begin{tabular}{cc}
\hline Vehicle ID & Fuel saving \% \\
1 & $-7.30 \%$ \\
2 & $-5.81 \%$ \\
3 & $-2.04 \%$ \\
4 & $-3.09 \%$ \\
5 & $1.71 \%$ \\
6 & $-6.29 \%$ \\
7 & $-2.92 \%$ \\
8 & $-3.40 \%$ \\
\hline
\end{tabular}

Fuel consumption results for all 8 drivers are shown in Table 2. This table shows the difference in the average of the weekly fuel consumption values, before and after the drivers took a course on fuel-efficient driving. The number of weeks monitored after the eco-driving course differs from driver to driver, and varies from 4 to 18 weeks. 
For 7 of the 8 drivers, fuel consumption diminished (as was expected) in the range of 1.7 to $7.3 \%$. For one driver, fuel consumption actually increased slightly $(1.71 \%)$. When looking closer at the results for this particular driver, an improvement can be seen in the first three weeks after the course (around 5\%), after which the driver falls back to his/her old habits, increasing fuel consumption again. It should be noticed that none of the drivers received any feedback on their driving style or fuel consumption results during the monitoring period.

At this point of the study, a multivariate analysis on the data to estimate the effect of the different aspects of a person's driving style on their fuel consumption has not yet been performed.

\section{Conclusion}

During several months, the fuel consumption and driving behaviour of 28 respondents was monitored by logging GPS data on position and speed, together with various CAN-parameters (e.g. revs per minute, chosen gear etc.). For 8 drivers that have taken an eco-driving course, weekly averages in fuel consumption were compared for several weeks 'before' and 'after' the course, together with the averages in gear-shifting rpm-values, relative amount of hard acceleration, relative amount of large RPA values, and relative amount of time of letting the car roll in gear. For 7 of the 8 drivers, fuel consumption diminished (as was expected) in the range of 1.7 to $7.3 \%$. For one driver, fuel consumption actually increased slightly $(1.71 \%)$ when measured over a period of 8 weeks, in spite of an improvement of 5\% in the first 3 weeks after his course.

\section{References}

[1] Landuyt, R., Van Brempt, K., Bond Beter Leefmilieu (2007). Resultaten pilootproject ecologisch rijden bij bedrijven. http://www. mobielvlaanderen.be, 10/01/2007

[2] SenterNovem (2007). Het Nieuwe Rijden. http://www.senternovem.nl/ het nieuwe rijden, 12/01/2007.

[3] De ${ }^{-}$Vlieger, I., De Keukeleere, D. \& Kretzschmar, J.G. (2000). Environmental effects of driving behaviour and congestions related to passenger cars. Atmospheric Environment, Vol. 34, p. 4649-4655.

[4] Int Panis, L., De Vlieger, I., Pelkmans, L. \& Schrooten, L. (2006a). Effect of speed reduction on fuel consumption and emissions of heavy duty lorries in Belgium. Proceedings of the 8th International conferences on Highways and the Urban Environment (HUES 2006), Nicosia, Cyprus, In Press.

[5] Int Panis, L., Beckx, C. \& Broekx, S. (2006b). Impact of zone 30 introduction on vehicle exhaust emissions in urban areas. Proceedings of the European Transportation Conference Strasbourg France, 2006. In prep

[6] BBL, Bond Beter Leefmilieu (2007). Eco-driving. http://www.bblv.be, $12 / 01 / 2007$. 
[7] Fortis (2006). Fortis - praktisch. http://www.fortis.be/praktisch, 12/01/2007.

[8] Wipfler, R. (1995). Energiesparendes und umweltschonendes Autofahren. Umweltforschungsinst. Tübingen, Germany.

[9] Wilbers, P. (1997). Energiebewust rijden in de rij-opleiding voor het $B$ rijbewijs. Novem, The Netherlands, 06/1997.

[10] Johansson, H. (1999). Impact of eco-driving on emissions and fuel consumption. Swedish National Road Administration, 20/12/1999.

[11] Hornung, D. (2001). Evaluation der Eco-Drive Simulations-Kurse. QAED, Switzerland, 11/2001.

[12] Van Mierlo, J., De Bisschop, E., Van de Burgwal, E., Bremmers, D. \& Gense, R. (2002). Invloed van het rijgedrag op de verkeersemissies: kwantificatie en maatregelen. Study commissioned by the Flemish Environmental Administration.

[13] DfT, Department for Transport (2006). Light Commercial Vehicle (LCV) SAFED Pilot Scheme Handout. http://www.dft.gov.uk, 25/01/2006.

[14] Bruneel, H., Govaerts, L. \& Craps, R. (2000). Acties ter bevordering van energiezuinig en veilig rijgedrag. VITO, Mol, Belgium, 07/2000.

[15] Govaerts, L. \& Verlaak, J. (2003). Eco-driving in a company fleet. Final report Belgian pilot. VITO, Mol, Belgium, 23/01/2003.

[16] Beckx, C., Int Panis, L., Debal, P. \& Wets, G. (2006). Influence of gear changing behaviour on fuel-use and vehicular exhaust emissions. Proceedings of the 8th International conferences on Highways and the Urban Environment (HUES 2006), Nicosia, Cyprus, In Press.

[17] Correia J.T., Iliadis K.A., McCarron E.S. and Smolej M.A. (2001) Utilizing data from automotive event data recorders, Proceedings of the Canadian Multidisciplinary Road Safety Conference XII, London Ontario.

[18] Toledo, G., Shiftan, Y., Hakkert, S. (2007). Framework for Analysis and Modeling of Driving Behavior. The Traffic Safety Center Newsletter, fall 2007, C3 803, Berkeley.

[19] Roetting M., Huang Y.H., McDevitt J.R., Melton D. (2003) When technology tells you how you drive-truck drivers' attitudes towards feedback by technology Transportation Research Part F: Traffic Psychology and Behavior, Vol. 6, Issue 4, pp. 275-287.

[20] Wouters P.I.J., Bos J.M.J. (1997) The Impact of Driving Monitoring with Vehicle Data Recorders on Accident Occurrence. Methodology and Results of a Field Trail in Belgium and the Netherlands. SWOV, Institute for Road Safety Research, R-97-8. 